\title{
CORRECTION
}

\section{Correction to: Clinical analysis of 12 patients with primary lymphoepithelial carcinoma of the parotid gland}

\author{
Dong-feng Deng ${ }^{1} \cdot$ Qin Zhou ${ }^{1} \cdot$ Zhuo-miao Ye $^{1} \cdot$ Zhe Xu $^{2} \cdot$ Lin Shen $^{1}$
}

Published online: 25 September 2021

๑) Springer-Verlag GmbH Germany, part of Springer Nature 2021

\section{Correction to: European Archives of Oto-Rhino-Laryngology \\ https://doi.org/10.1007/s00405-021-06947-7}

In the original publication of the article, the affiliation details for authors "Zhuo-miao Ye, Zhe Xu" were incorrectly given as "Zhuo-miao $\mathrm{Ye}^{2}$, $\mathrm{Zhe} \mathrm{Xu}^{1}$ " but should have been "Zhuo-miao $\mathrm{Ye}^{1}$, Zhe $\mathrm{Xu}^{2}$ ".

The original article was updated.

Publisher's Note Springer Nature remains neutral with regard to jurisdictional claims in published maps and institutional affiliations.

The original article can be found online at https://doi.org/10.1007/ s00405-021-06947-7.

Lin Shen

188101059@csu.edu.cn

1 Department of Oncology, Xiangya Hospital, Central South University, Changsha 410008, China

2 Department of Pharmacy, Xiangya Hospital, Central South University, Changsha 410008, China 